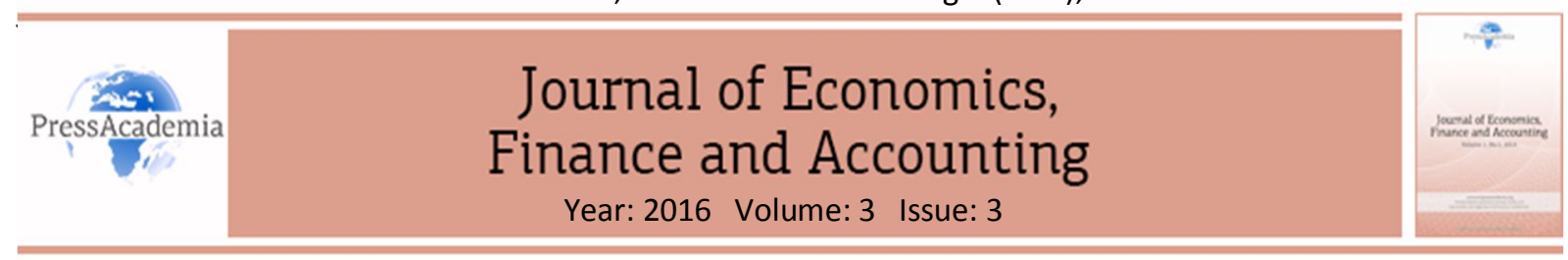

\title{
AN APPLICATION OF BENFORD'S LAW TO FUNDAMENTAL ACCOUNTING FIGURES REPORTED BY BORSA ISTANBUL (BIST) COMPANIES
}

\section{DOI: 10.17261/Pressacademia.2016321991}

\author{
Asli Aybars ${ }^{1}$, Levent Ataunal ${ }^{2}$ \\ ${ }^{1}$ Marmara University, asli.aybars@marmara.edu.tr \\ ${ }^{2}$ Istanbul Aydın University, leventataunal@aydin.edu.tr
}

\begin{abstract}
The financial reporting of public firms is argued for being subject to manipulation and fraud. Since adherence to this mysterious law is accepted as a sign for the data's reliability, Benford's Law has long been used by auditors as a tool to test the integrity of a dataset and to detect fraud. The expected distribution of digits in any set of natural numbers has initially been put forward by Benford (1938). Benford's law states that probability distribution of digits' occurrence is not uniform. Smaller digits are found to exist more frequently than the greater ones. This study tested the compliance of fundamental figures reported by Borsa Istanbul (BIST) companies with Benford's Law, by means of a data between 2005 and 2015 covering 148 companies. According to the different testing approaches utilized, which imparted rather similar results, reported figures of current assets and net sales seemed to be almost in perfect conformity with Benford's Law. However, the study detected several deviation points in the data of total assets and net profit figures from Benford's Law. From the results of this study, we cannot conclude that they are extensively manipulative or they are in full conformity with the Benford's Law. Nevertheless, this study suggests the possible point of interest for further researches. In application of Benford's Law non-conformity should be evaluated with discretion. The deviations are only a signal to a nalyze the data further, and should not be seen as a solid proof of fraud or manipulation.
\end{abstract}

Keywords: Benford's Law, Borsa Istanbul, manipulation, fraud, financial reporting JEL Classification: G30, M41, M42

\section{INTRODUCTION}

Manipulation, fraudulent activities, and flaws in reporting of accounting information have crucial impact on the reliability of financial statements. Correctness of publicized information is vital for well-functioning financial markets as it affects public perceptions. Misperceptions about firms may hinder proper functioning of financial markets resulting in inefficiencies in capital distribution. Stakeholders relentlessly strive to verify the quality of reported data. Accordingly, this study attempts to reveal whether major inputs in a set of published data is manipulated or not, by using Benford's law.

Benford's Law, which is explained in detail in the forthcoming sections, suggests a frequency distribution for digits in any tabulated data. The expected pattern of digit distribution based on this law can be used as a tool to check quality of data. Investigating the conformity of a dataset with Benford's Law can be seen as an auditing technique to detect fraud, errors, and fabrication in any transactional data. In summary, the law can be utilized to uncover the integrity of available data (Nigrini and Miller, 2007). Nevertheless, it is important to emphasize that even though Benford's Law can be used as a tool to test reliability of a dataset, non-conformity should be evaluated cautiously. Non-compliance is not always an indication of deliberate manipulation or human error. It may also stem from the inefficiencies in the generation of data. The deviation should be accepted as a signal to review and analyze the data more closely and should not, therefore, be seen as a solid proof of fraud. The process should be used as an initial tool to detect potential errors and manipulation that may exist in the dataset. 
The rest of the paper is organized as follows. The next section reviews the literature on Benford's Law. Section 3 explains the research approach and the data used. The subsequent section sets forth the analyses and the results. The last section concludes and suggests the limitations of the study.

\section{LITERATURE REVIEW}

The discovery of the phenomenon that the ten digits do not occur with equal frequency dates back to the study of Newcomb (1881). Simon Newcomb, an American astronomer, realized that first pages of books of logarithmic tables wore out much faster than the last pages. The idea that there is an expected distribution of digits in any dataset of natural numbers has been more strongly put forward by Benford (1938). In his study, the percentage of times the natural numbers from 1 to 9 occur in a dataset of more than 20,000 observations was analyzed. The sample covered numerous areas of data some of which can be named as atomic weights, population, river drainage, cost data, and items related to newspapers. He disclosed a tendency of a random nature in numbers. It was discovered that these 'outlaw' or 'anomalous' numbers agreed with logarithmic law. When the probability of occurrence of digits from the logarithmic scale is estimated, it is seen that $30 \%$ of the time a randomly selected number begins with 1, and this frequency is found to fall to $4.6 \%$ in case of 9 . The notion that defines the expected frequency of digits where smaller digits occur more frequently in the first position than larger digits, became known as Benford's law. This characteristic of numbers' distribution fits well with numbers of a random nature, but not with those of a formal or mathematical nature. The below Table 1 shows expected digital frequencies of Benford's Law for the first and second places.

Table 1: The First and Second Place Frequencies of Digits

\begin{tabular}{ccc}
\hline Digit & First Place & Second Place \\
\hline $\mathbf{0}$ & 0.000 & 0.120 \\
$\mathbf{1}$ & 0.301 & 0.114 \\
$\mathbf{2}$ & 0.176 & 0.108 \\
$\mathbf{3}$ & 0.125 & 0.104 \\
$\mathbf{4}$ & 0.097 & 0.100 \\
$\mathbf{5}$ & 0.079 & 0.097 \\
$\mathbf{6}$ & 0.067 & 0.093 \\
$\mathbf{7}$ & 0.058 & 0.090 \\
$\mathbf{8}$ & 0.051 & 0.088 \\
$\mathbf{9}$ & 0.046 & 0.085 \\
\hline
\end{tabular}

Source: Benford (1938)

An experiment was conducted to test the conformity of invented numbers with Benford's Law in the study of Hill (1988), in which 742 undergraduate calculus students were asked to create six digit random numbers. Digit 1 is found to occur more frequently than digits 8 or 9 in the first place though not in perfect conformity with the Law. Diekmann (2007) evaluated the same matter on both published and fabricated statistical estimates. Benford's distribution was found to conform with the published data. In the test of fabricated data, the subjects, who were students of University of Berne in Switzerland, were asked to construct regression coefficients on a certain hypothesis. Although the distribution of first digit was in line with the predictions of the law, the second digit was found to demonstrate deviation from the expected figures of the law. The conclusion was that rightmost digits in fabricated data demonstrated to be better clues for potential errors.

Durtschi et al. (2004) specified the cases when it would be appropriate to utilize Benford's Law. Accounts that were comprised of numbers resulting from mathematical combinations and accounts that display transactions, large datasets and the cases where the mean was greater than the median with positive skewness were the situations when the law could be applied. In cases where dataset was made up of assigned numbers or when human thought affected the numbers, it was not appropriate to use the law. Furthermore, accounts that were restricted by minimum or maximum values and those that were made of numbers specific to the firm were not 
suitable to be tested by the law. Table 2 summarizes the context when Benford's Law is useful and when it has to be applied rather cautiously.

The idea to utilize Benford's Law in compliance research is not new. Some of the initial studies can be named as those of Slemrod (1985) and Nigrini (1996). The idea is to test whether the human element causes the digits of the reported numbers to deviate from expected frequencies. Thomas (1989) tested for the presence of earnings management by utilizing the natural occurrence of digit frequencies in detecting whether managers round earnings numbers to reach their goals.

Table 2: When Tt is Appropriate to Use Benford's Law

\begin{tabular}{|c|c|}
\hline When Benford Analysis is Likely Useful & Examples \\
\hline $\begin{array}{l}\text { Sets of numbers that result from mathematical } \\
\text { combination of numbers - Result comes from two } \\
\text { distributions }\end{array}$ & $\begin{array}{l}\text { Accounts receivable (number sold * price), } \\
\text { Accounts Payable (number bought * price) }\end{array}$ \\
\hline Transaction-level data - No need to sample & Disbursements, sales, expenses \\
\hline On large data sets - The more observations, the better & Full year's transactions \\
\hline $\begin{array}{l}\text { Accounts that appear to conform - When the mean of a } \\
\text { set of numbers is greater than the median and the } \\
\text { skewness is positive }\end{array}$ & Most sets of accounting numbers \\
\hline When Benford Analysis is not Likely Useful & Examples \\
\hline Data set is comprised of assigned numbers & Check numbers, invoice numbers, zip codes \\
\hline Numbers that are influenced by human thought & $\begin{array}{l}\text { Prices set at psychological thresholds (\$1.99), ATM } \\
\text { withdrawals }\end{array}$ \\
\hline Accounts with a large number of firm-specific numbers & An account specifically set up to record $\$ 100$ refunds \\
\hline Accounts with a built in minimum or maximum & Set of assets that must meet a threshold to be recorded \\
\hline Where no transaction is recorded & Thefts, kickbacks, contract rigging \\
\hline
\end{tabular}

Source: Durtschi et al, 2004, pp.24

Recent studies have been performed on accounting data for detection of fraud as well. Alali and Romero (2013) utilized financial accounting data to observe whether any deviations from Benford's Law exist on U.S. publicly available data for the decade starting at year 2001. Based on the analyses of first and the first-two digits of data in different periods and for different firm sizes, a likely manipulation was detected. Effectiveness of regulations, greater scrutiny, and being audited by Big 4 firms were important factors affecting the degree of manipulation. A concurrent study performed on European publicly listed companies was that of Grabinski and Paszek (2013) which tested selected accounting items; namely, net profit, equity, sales, total assets and profitability ratios generated by these items with respect to their consistency with Benford's Law. The distribution of accounting items was found to be in conformity with the theoretical distribution postulated by the law. A divergence from the law was detected in the case of financial ratios, though it was at an acceptable level for the cases of return on sales and return on equity.

Benford's Law has also been used to test the quality of macroeconomic data announced by governments. Accordingly, Rauch et al. (2011) utilized a data set of public deficit, public debt, and gross national product which was extracted from Eurostat database belonging to $27 \mathrm{EU}$ member states for the period between 1999 and 2009. The findings revealed that, with respect to the first digit, Greece, Romania, Latvia, and Belgium were the countries with the most deviating data from Benford's Law. However, it has to be reiterated that deviation should not be considered as a direct sign of manipulation, it essentially suggests a further investigation in the case of non-conformities. Another study that tested for the conformity of international macroeconomic statistics with Benford's Law was that of Nye and Moul (2007). Analyses were conducted on a dataset of 183 countries together with a further investigation into a subset of OECD countries. Overall the findings showed that while data belonging to OECD countries was consistent with the law, some non-conformities in the GDP figures of developing countries were existed. 
Similarly, Data from Borsa Istanbul (BIST) has also been tested for conformity with Benford's Law. A recent study by Cinko (2014) tested the compliance of the returns of stocks listed on BIST-100 between the dates 02.01.1990 and 02.12.2013. When the whole period analyzed using Chi-square statistic, it was seen that the distribution of the returns does not fit with the law. However, when the data was analyzed after being segregated into three periods, only the third period was found to be non-corresponding to the law. The returns' distributions in the first and second periods were found to be in accordance with the law. Gönen and Rasgen (2016) tested the existence of fraud in transactions of three public companies listed on BIST. The volume of transactions belonging to the selected companies was examined by using first digit, second digit and first-two digit tests. Non-conformity to Benford's Law was detected in the company that was suspected of engaging in manipulative activities. Another study utilizing first digit test was conducted on consolidated 2013 first quarter figures of four banks listed on BIST for (Uzuner, 2014). The results of the Chi-square test statistic revealed the accordance of first digit distribution with the law.

It is important to emphasize that even though Benford's Law can be used as an important tool to test the integrity of a dataset, non-conformity should be evaluated with extreme caution. Non-correspondence to Benford's distribution does not always mean that the dataset is deliberately manipulated or any human error is involved, but that, there may exist inefficiencies in the generation of data. The deviation should be accepted as a signal to review and analyze the data more closely and should not, therefore, be seen as a solid proof of fraud. Overall, the process should be used as an initial tool to see whether any potential errors exist in the dataset or in the data transformation process.

\section{DATA AND METHODOLOGY}

As stated in the previous sections, Benford's Law provides the expected frequencies of the digits in a dataset. It basically claims that smaller digits (like 1, 2, and 3) should be observed more frequently than the bigger digits. Several different approaches are possible for examining compliance of numbers with Benford's Law. Naturally, number set may include negative numbers, however, according to Benford's Law, the first digit is the first nonzero digit. Minus signs should be ignored and the digit following the negative sign should be accepted as the first digit. Benford's law states that the logarithmic pattern in the numbers can be expressed with the probability of observation of each digit in specific location. Thus, the probability of observing a certain number in the first digit is estimated with the following logarithmic equation.

$$
P(d)=\log _{10}(d+1)-\log _{10}(d) \quad d \in\{1 \ldots \ldots 9\}
$$

Equation (1) states that probability of occurrence of digit $d$ is proportional to the space between $d$ and $d+1$ on a logarithmic scale. In other words, probability of occurrence of two consecutive digits is at equal distance on the logarithmic scale. Equation (1) can be simplified as:

$$
P(d)=\log _{10} \frac{d+1}{d}=\log _{10}\left(1+\frac{1}{d}\right)
$$

Furthermore, the two digit probabilities can be denoted as in Equation (3):

$$
P\left(d_{1} d_{2}\right)=\log _{10}\left(1+\frac{1}{d_{1} d_{2}}\right) \quad d_{1} d_{2} \in\{11,12 \ldots \ldots . .99\}
$$

when probabilities of numbers $12,22,32,42 \ldots . .92$, are added, the probability of occurrence of 2 as the second digit can be estimated.

Financial reporting of public companies has long been criticized for being exposed to manipulation and fraud. Earnings management has shown to be an important problem affecting the quality and correctness of financial reporting. Many studies verified managers' tendency to manipulate their earnings according to expectations in the market (Hadani et al.,2010; Zahra et al., 2005; Liu, 2005; Koh, 2007). Undisclosed fraud in a firm may also affect the reported figures of the firm. Benford's Law could help to detect the extent of manipulation and fraud within the reported figures.

To demonstrate the reporting quality and the extent of manipulation in BIST, this study tested some of the annually reported fundamental figures for compliance with Benford's Law. In the analysis, 11 years data 
(between 2005 and 2015) of 148 non-financial companies is employed. Only the most basic financial reporting figures are chosen for testing namely, net sales, total assets, current assets and net profit/loss. So for each reported figure, 1628 numbers are analyzed for conformity with the Bedford's Law. Chi-square $\left(\chi^{2}\right)$ and $Z$ tests are applied to first two digits of data. Also a joint analysis of first two digits is made where results are presented in graphical form.

Table 3: First Digit Frequencies

\begin{tabular}{|c|c|c|c|c|c|c|c|c|c|}
\hline \multirow[b]{2}{*}{ Digits } & \multicolumn{2}{|c|}{ Total Assets } & \multicolumn{2}{|c|}{ Current Assets } & \multicolumn{2}{|c|}{ Net Profit } & \multicolumn{2}{|c|}{ Net Sales } & \multirow{2}{*}{$\begin{array}{c}\text { Benford's Lav } \\
\underline{\text { 1st digit }} \\
\underline{\text { rrequency }}\end{array}$} \\
\hline & $\begin{array}{c}\text { \# of } \\
\text { Observations }\end{array}$ & Frequency & $\begin{array}{c}\text { \# of } \\
\text { Observations }\end{array}$ & Frequency & $\begin{array}{c}\text { \# of } \\
\text { Observations }\end{array}$ & Frequency & $\begin{array}{c}\text { \# of } \\
\text { Observations }\end{array}$ & Frequency & \\
\hline 1 & 471 & 0.2893 & 513 & 0.3151 & 476 & 0.2924 & 524 & 0.322 & 0.3010 \\
\hline 2 & 330 & 0.2027 & 298 & 0.1830 & 317 & 0.1947 & 294 & 0.181 & 0.1761 \\
\hline 3 & 225 & 0.1382 & 198 & 0.1216 & 202 & 0.1241 & 186 & 0.114 & 0.1249 \\
\hline 4 & 151 & 0.0928 & 156 & 0.0958 & 139 & 0.0854 & 145 & 0.089 & 0.0969 \\
\hline 5 & 138 & 0.0848 & 115 & 0.0706 & 130 & 0.0799 & 116 & 0.071 & 0.0792 \\
\hline 6 & 115 & 0.0706 & 107 & 0.0657 & 109 & 0.0670 & 119 & 0.073 & 0.0669 \\
\hline 7 & 78 & 0.0479 & 75 & 0.0461 & 91 & 0.0559 & 96 & 0.059 & 0.0580 \\
\hline 8 & 76 & 0.0467 & 85 & 0.0522 & 100 & 0.0614 & 82 & 0.050 & 0.0512 \\
\hline 9 & 44 & 0.0270 & 81 & 0.0498 & 64 & 0.0393 & 66 & 0.041 & 0.0458 \\
\hline
\end{tabular}

Table 4: Second Digit Frequencies

\begin{tabular}{|c|c|c|c|c|c|c|c|c|c|}
\hline \multirow[b]{2}{*}{ Digits } & \multicolumn{2}{|c|}{ Total Assets } & \multicolumn{2}{|c|}{ Current Assets } & \multicolumn{2}{|c|}{ Net Profit } & \multicolumn{2}{|c|}{ Net Sales } & \multirow{2}{*}{$\begin{array}{c}\text { Benford's Law } \\
\underline{\text { 2nd digit }} \\
\underline{\text { frequency }}\end{array}$} \\
\hline & $\begin{array}{c}\text { \# of } \\
\text { Observations }\end{array}$ & Frequency & $\begin{array}{c}\text { \# of } \\
\text { Observations }\end{array}$ & Frequency & $\begin{array}{c}\text { \# of } \\
\text { Observations }\end{array}$ & Frequency & $\begin{array}{c}\text { \# of } \\
\text { Observations }\end{array}$ & Frequency & \\
\hline 0 & 166 & 0.1020 & 196 & 0.1204 & 187 & 0.1149 & 206 & 0.127 & 0.1197 \\
\hline 1 & 201 & 0.1235 & 199 & 0.1222 & 178 & 0.1093 & 199 & 0.122 & 0.1139 \\
\hline 2 & 186 & 0.1143 & 184 & 0.1130 & 180 & 0.1106 & 182 & 0.112 & 0.1088 \\
\hline 3 & 179 & 0.1100 & 158 & 0.0971 & 163 & 0.1001 & 165 & 0.101 & 0.1043 \\
\hline 4 & 157 & 0.0964 & 185 & 0.1136 & 161 & 0.0989 & 155 & 0.095 & 0.1003 \\
\hline 5 & 154 & 0.0946 & 147 & 0.0903 & 156 & 0.0958 & 156 & 0.096 & 0.0967 \\
\hline 6 & 138 & 0.0848 & 138 & 0.0848 & 147 & 0.0903 & 133 & 0.082 & 0.0934 \\
\hline 7 & 143 & 0.0878 & 151 & 0.0928 & 177 & 0.1087 & 155 & 0.095 & 0.0904 \\
\hline 8 & 153 & 0.0940 & 142 & 0.0872 & 132 & 0.0811 & 134 & 0.082 & 0.0876 \\
\hline 9 & 151 & 0.0928 & 128 & 0.0786 & 147 & 0.0903 & 143 & 0.088 & 0.0850 \\
\hline
\end{tabular}

\section{FINDINGS AND DISCUSSIONS}

Observed proportions of first and second digits and the expected proportions of Benford's Law are given in Table 3 and in Table 4. For several reasons only the compliance of first two digits is tested. First, manipulation in the first digits has the biggest impact on the finally reported figure. Eventually it has the biggest impact on investors' perception of the firm. Secondly, first digits are least affected from rounding. Subsequent digits may be more affected especially from the rounding in provisional figures (Engel, 2011).

\subsection{Chi-square Test}

To evaluate the observations' compliance with Benford's law, initially chi-square test $\left(\chi^{2}\right)$ is utilized. The chisquare test may be used to measure the goodness-of-fit of data at hand to Benford's Law (Nigrini and Miller 2007). Chi-square statistic is calculated as follows:

$$
\chi^{2}=n \sum_{i=1}^{9} \frac{\left(O_{i}-P_{i}\right)^{2}}{P_{i}} \quad \text { for the first digit and }
$$




$$
\chi^{2}=n \sum_{i=0}^{9} \frac{\left(O_{i}-P_{i}\right)^{2}}{P_{i}} \quad \text { for the second digit }
$$

where $\mathrm{n}$ is the number of observations, which is 1628. $O_{i}$ is the observed frequency of the digit and $P_{i}$ is the expected frequency of the digit according to Benford's law.

The chi-square statistics are given in Table 5 . The $p$-values are estimated with $d f=8$ (degrees of freedom) for the $1^{\text {st }}$ digit and with $\mathrm{df}=9$ for the $2^{\text {nd }}$ digit.

Table 5: Chi-square Statistics Test Results

\begin{tabular}{lcccc}
\hline & 1st Digit & \multicolumn{2}{c}{ 2nd Digit } \\
\hline & $\boldsymbol{\chi}^{\mathbf{2}}$ & $\mathbf{P}$ - value & $\boldsymbol{\chi}^{\mathbf{2}}$ & $\mathbf{P}$ - value \\
\hline Total Assets & $\mathbf{2 6 . 8 1 7 4}$ & $\mathbf{0 . 0 0 0 8}$ & 10.1504 & 0.3384 \\
Current Assets & 7.8143 & 0.4518 & 7.8381 & 0.5505 \\
Net Profit & 10.8235 & 0.2119 & 8.5444 & 0.4803 \\
Net Sales & 8.2838 & 0.4063 & 5.8123 & 0.7585 \\
\hline
\end{tabular}

According to chi-square $\left(\chi^{2}\right)$ test, only the first digit of reported total assets figures indicates a potential nonconformity with Benford's law. The rest of the digits seem to be in harmony with the expected proportions of Benford's law.

\subsection{Z-statistic}

To further explore the robustness of the results and to detect possible non-conformity in a specific digit, as also suggested by Nigrini (1996) and Durtschi et al.(2004), Z-statistic test is employed. The standard deviation for each digit's expected proportion is estimated with equation (6).

$$
s_{i}=\sqrt{\frac{P_{e i}\left(1-P_{e i}\right)}{n}}
$$

where $\mathrm{n}$ is the sample size and $P_{e i}$ is the expected proportion of digit $\mathrm{i}$ according to the Benford's Law. Then, the $z$-statistic is estimated as with equation (7).

$$
Z_{i}=\frac{\left|P_{o i}-P_{e i}\right|-\frac{1}{2 n}}{s_{i}}
$$

where $P_{o i}$ is the observed proportion of digit i, $P_{e i}$ is the expected proportion of digit i according to Benford's Law. Estimated z-statistic values and the $p$-values against the null hypothesis that the observed digit is in

\begin{tabular}{|c|c|c|c|c|c|c|c|c|c|}
\hline \multirow[b]{2}{*}{ 1st Digit } & \multirow[b]{2}{*}{ Si } & \multicolumn{2}{|c|}{ Total Assets } & \multicolumn{2}{|c|}{ Current Assets } & \multicolumn{2}{|c|}{ Net Profit } & \multicolumn{2}{|c|}{ Net Sales } \\
\hline & & z-value & p-value & z-value & p-value & z-value & p-value & z-value & p-value \\
\hline 1 & 0.0114 & 1.0011 & 0.3168 & 1.2142 & 0.2247 & 0.7309 & 0.4648 & 1.8086 & 0.0705 \\
\hline 2 & 0.0094 & 2.7854 & 0.0053 & 0.7033 & 0.4819 & 1.9396 & 0.0524 & 0.4430 & 0.6577 \\
\hline 3 & 0.0082 & 1.5865 & 0.1126 & 0.3626 & 0.7169 & 0.0628 & 0.9500 & 1.2622 & 0.2069 \\
\hline 4 & 0.0073 & 0.5239 & 0.6004 & 0.1050 & 0.9164 & 1.5293 & 0.1262 & 1.0266 & 0.3046 \\
\hline 5 & 0.0067 & 0.7858 & 0.4320 & 1.2332 & 0.2175 & 0.0516 & 0.9588 & 1.1415 & 0.2537 \\
\hline 6 & 0.0062 & 0.5542 & 0.5794 & 0.1402 & 0.8885 & -0.0410 & 1.0327 & 0.9510 & 0.3416 \\
\hline 7 & 0.0058 & 1.6884 & 0.0913 & 2.0065 & 0.0448 & 0.3100 & 0.7565 & 0.1141 & 0.9092 \\
\hline 8 & 0.0055 & 0.7707 & 0.4409 & 0.1289 & 0.8974 & 1.8156 & 0.0694 & 0.0960 & 0.9235 \\
\hline 9 & 0.0052 & 3.5641 & 0.0004 & 0.7039 & 0.4815 & 1.1929 & 0.2329 & 0.9558 & 0.3392 \\
\hline
\end{tabular}
conformity with Benford's Law are given in Tables 5 and 6.

Table 6: Z-values and P-values of $1^{\text {st }}$ Digits 
When we assume a significance level of $5 \%(\alpha=0.05)$ in the first digit level, digits ' 2 ' and ' 9 ' in totals assets appear to deviate from Benford's Law (Table 6). When we also assume the same significance level $(\alpha=0.05)$ in the second digit level, digits ' 0 ' in the sample of total assets and digit ' 7 ' in the sample of net profit seem to diverge from Benford's Law (Table 7).

Table 7: Z-values and P-values of $2^{\text {nd }}$ Digits

\begin{tabular}{ccccccccccc}
\hline & \multicolumn{4}{c}{ Total Assets } & \multicolumn{2}{c}{ Current Assets } & \multicolumn{2}{c}{ Net Profit } & \multicolumn{2}{c}{ Net Sales } \\
2nd Digit & $\mathbf{S i}$ & z-value & p-value & z-value & p-value & z-value & p-value & z-value & p-value \\
\hline $\mathbf{0}$ & 0.0080 & $\mathbf{2 . 1 6 3 8}$ & $\mathbf{0 . 0 3 0 5}$ & 0.0506 & 0.9597 & 0.5603 & 0.5753 & 0.8141 & 0.4156 \\
$\mathbf{1}$ & 0.0079 & 1.1770 & 0.2392 & 1.0210 & 0.3073 & 0.5393 & 0.5897 & 1.0210 & 0.3073 \\
$\mathbf{2}$ & 0.0077 & 0.6636 & 0.5069 & 0.5045 & 0.6139 & 0.1861 & 0.8524 & 0.3453 & 0.7299 \\
$\mathbf{3}$ & 0.0076 & 0.7014 & 0.4830 & 0.9201 & 0.3575 & 0.5147 & 0.6068 & 0.3526 & 0.7244 \\
$\mathbf{4}$ & 0.0074 & 0.4786 & 0.6322 & 1.7489 & 0.0803 & 0.1486 & 0.8818 & 0.6437 & 0.5198 \\
$\mathbf{5}$ & 0.0073 & 0.2424 & 0.8085 & 0.8295 & 0.4068 & 0.0747 & 0.9405 & 0.0747 & 0.9405 \\
$\mathbf{6}$ & 0.0072 & 1.1511 & 0.2497 & 1.1511 & 0.2497 & 0.3845 & 0.7006 & 1.5771 & 0.1148 \\
$\mathbf{7}$ & 0.0071 & 0.3106 & 0.7561 & 0.2945 & 0.7684 & $\mathbf{2 . 5 4 2 2}$ & $\mathbf{0 . 0 1 1 0}$ & 0.6403 & 0.5220 \\
$\mathbf{8}$ & 0.0070 & 0.8712 & 0.3837 & 0.0056 & 0.9955 & 0.8824 & 0.3776 & 0.7070 & 0.4795 \\
$\mathbf{9}$ & 0.0069 & 1.0775 & 0.2813 & 0.8777 & 0.3801 & 0.7220 & 0.4703 & 0.3665 & 0.7140 \\
\hline
\end{tabular}

According to the results of both chi-square and z-statistic tests, both current assets and net sales figures seem to perfectly comply with Benford's Law's expected proportions. However, chi-square test hints a possible deviation in reported figures of total assets from the Benford's Law. Z-statistic test implies that, in total assets at the first digit level, the deviation may stem from digits ' 2 ' and ' 9 '. On the other hand, at second digit level, $z$ statistic indicates a possible divergence in the digit ' 0 ' of total assets and in the digit ' 7 ' of net profit figures. Accordingly, when in-depth analysis of possible manipulation is aimed, one must first examine the reported numbers starting with these digits and the related transactions.

\subsection{Joint Analysis of First Two Digits}

Most of the prior studies in the field of Benford's Law have focused on first or second digits. However, the joint analysis of first-two digits may also disclose anomalies that would be missed with the sole analysis of the first or second digits (Nigrini and Miller 2007). In this respect, the observed frequencies of first two digits are plotted against the expected frequencies of Benford's Law in Figures 1, 2, 3 and 4. The graphs exhibit the expected frequencies of Benford's Law against the actually observed data. As prior tests also suggested, current assets and net sales figures demonstrate a better matching with Benford's proportions in comparison to total assets and net profit figures. In total assets (Figure 1), the observed data seem to deviate from the expected proportions around 20's and 90's (first 2 digits) which is similar to the implications of Z-statistic tests. In the net sales data, some deviation seems to occur around the first digit of ' 1 ' (Figure 4). Although net sales seemed to passed the $z$-statistic, it barely did so ( $p=0.07$ against $\alpha=0.05)$. (Table 5$)$. 
Figure 1:

Combined Proportions of First Two Digits Against Benford's Law in Total Assets

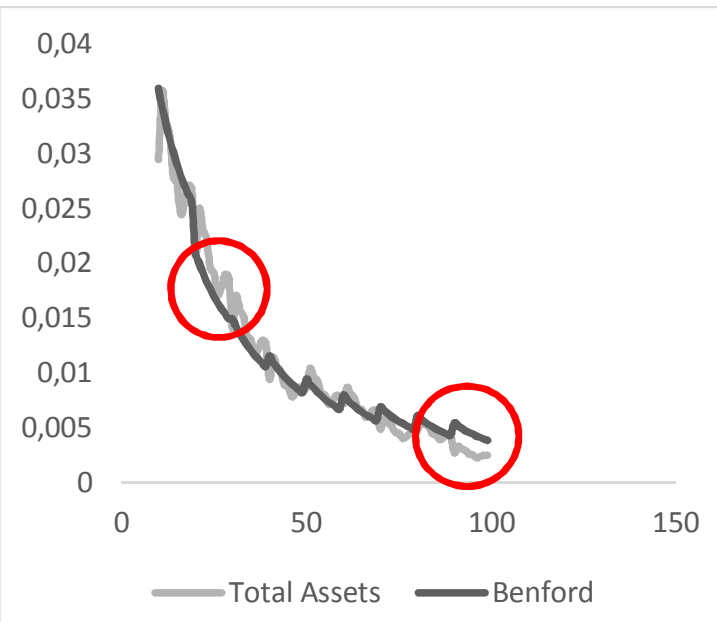

Figure 2:

Combined Proportions of First Two digits Against Benford's Law in Current Assets

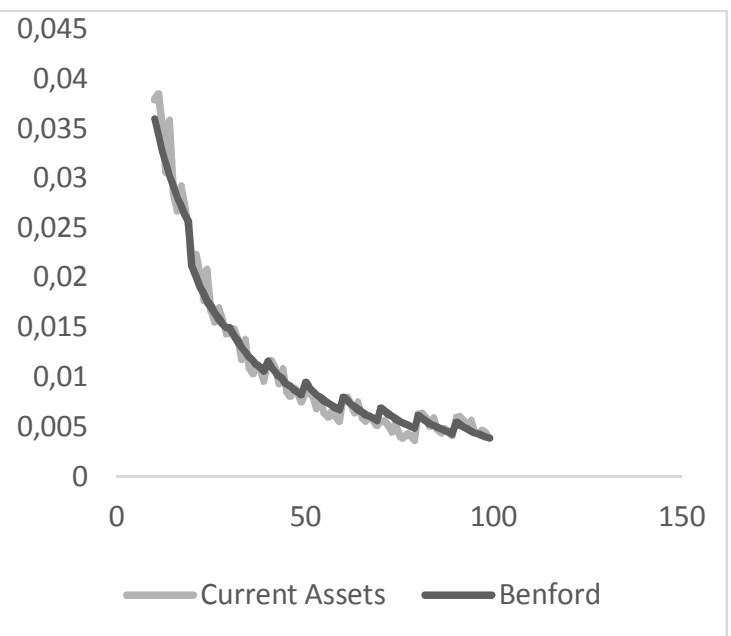

Although, some deviation is detected from Benford's Law using the chi-square and z-statistic tests, in general, major financial figures reported in BIST seem to be quite in accordance with the Bedford's Law. Small deviations disclosed do not lead to the conclusion that the reported figures are subject to substantial manipulation or fraud. However, when further investigation is required, the numbers which have to be analyzed in-depth initially, should be the ones which are indicated by this analysis. The different approaches adopted here found to be inter-changeably applicable. They seem to identify same deviation points in most cases.

Figure 3:

Combined Proportions of First Two Digits Against Benford's Law in Net profit

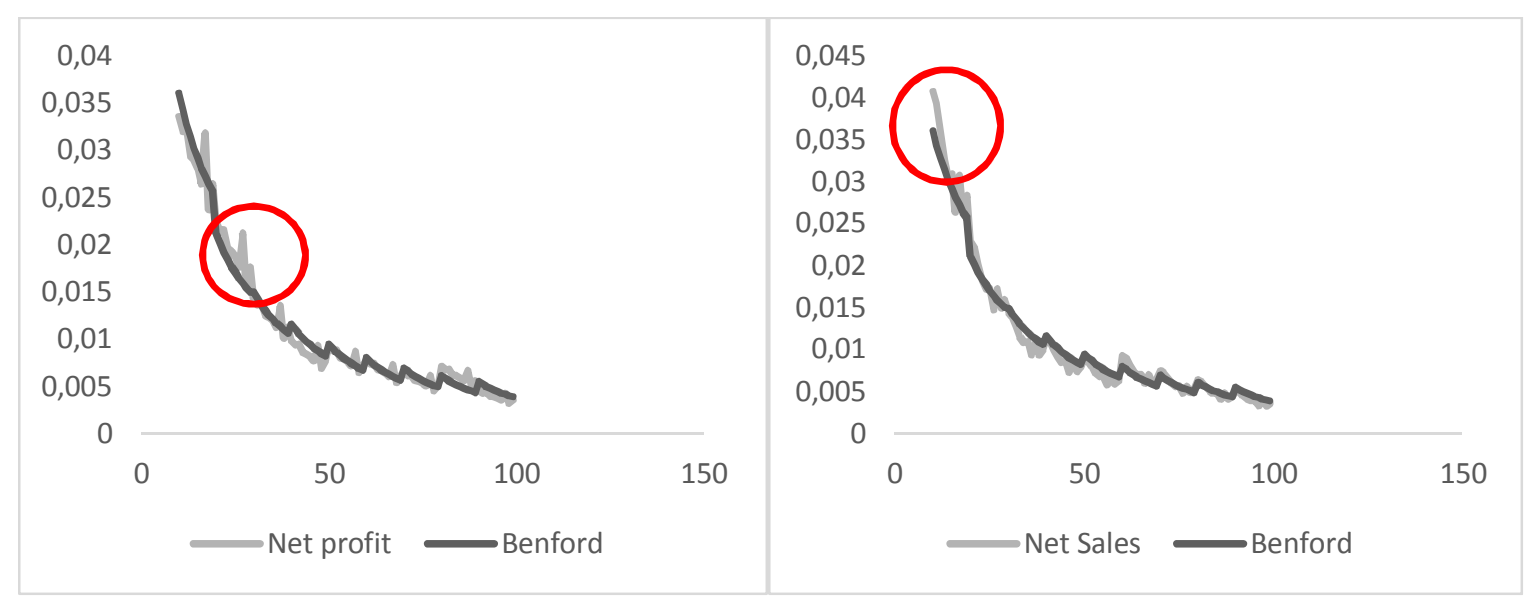

Figure 4:

Combined Proportions of First Two Digits Against Benford's Law in Net Sales

\section{CONCLUSION}

Benford's Law gives the expected frequencies of the digits in any numerical data, and it is widely used for testing the reliability of accounting information. It is applicable to diverse set of financial data and frequently used by the auditors to detect fraud, manipulation or fabrication in the accounting data. However, Benford's Law does not prescribe a sure way to detect fraud or manipulation, rather it pinpoints problem areas which may potentially be manipulative data. It is a useful tool to help identify some numbers for in-depth analysis. It 
simply narrows the dataset by detecting the data falling outside of expected pattern, which should be thoroughly examined.

The financial reporting of firms has long been known to be subject to manipulation and fraud. This paper aimed to measure the compliance of fundamental figures reported by BIST companies with Benford's Law. According to the different assessment approaches utilized for the first two digits, namely chi-square $\left(\chi^{2}\right)$ test, Z-test and joint analysis of first two digits, reported figures of current assets and net sales between 2005 and 2015 seemed to be almost in perfect conformity with Benford's Law. However, analysis detected several deviation points in the data of total assets and net profit figures from Benford's Law. The analyzing methods applied in this study certainly do not lead into the strong conclusion that they are extensively manipulative or they are in full conformity with Bedford's Law, they only suggest the point of interest for further researchers. Only a deeper analysis, probably at the transaction level, may disclose actual gaming of the data, if it actually exists.

\section{REFERENCES}

Alali, F. A., and Romero, S. 2013, "Benford's Law: Analyzing a Decade of Financial Data", Journal of Emerging Technologies in Accounting, vol. 10, pp. 1-39.

Benford, F. 1938, "The Law of Anomalous Numbers", Proceedings of the American Philosophical Society, vol. 78, no. 4, pp. 551-572.

Çinko, M. 2014, "Testing Distribution of BIST-100 Returns by Benford Law", Journal of Economics, Finance and Accounting, vol. 1, issue 3, pp. 184-191.

Diekmann, A. 2007, “Not the First Digit! Using Benford's Law to Detect Fraudulent Scientific Data”, Journal of Applied Statistics, vol. 34, no. 3, pp. 321-329.

Durtschi, C., Hillison W. , and Pacini, C. 2004, "The Effective Use of Benford's Law to Assist in Detecting Fraud in Accounting Data", Journal of Forensic Accounting, vol. V., pp. 17-34.

Engel, S. 2011, "Fact and Fiction in EU-Governmental Economic Data", German Economic Review, vol. 12, no.3, pp.243-255.

Gönen, S., and Rasgen, M. 2016, "Hile Denetiminde Benford Yasası: Borsa İstanbul Örneği”, Journal of International Trade, Finance and Logistics, vol.1, no.1, pp. 93-113.

Grabinski, K. and Paszek, Z. 2013, "Examining the Reliability of Large Financial Datasets Using Benford's Law”, Ekonomske Teme, vol. 51, no. 3, pp. 515-524.

Hadani, M., Goranova, M., Khan, R. 2010, "Institutional Investors, Shareholder Activism, and Earnings Management", Journal of Business Research. Vol. 64, no.12, pp. 1352-1360.

Hill, T. P. 1988, "Random-Number Guessing and the First Digit Phenomenon”, Psychological Reports, vol. 62, pp. 967-971.

Koh, P-S. 2007, "Institutional Investor Type, Earnings Management and Benchmark Beaters", Journal of Accounting and Public Policy. vol. 26, pp. 267-299.

Liu, A. Z. 2005, "The Role of Financial Analysts and Institutional Investors in the Numbers Game". Available at SSRN: http://ssrn.com/abstract=705385 or http://dx.doi.org/10.2139/ssrn.705385.

Newcomb, S. 1881, "Note on the Frequency of Use of the Different Digits in Natural Numbers", American Journal of Mathematics, vol. 4, no. 1. , pp. 39-40.

Nigrini, M. J. 1996, “A Taxpayer Compliance Application of Benford's Law”, The Journal of the American Taxation Association, vol. 18., no. 1, pp. 72-91.

Nigrini, M. J., Miller, S. J. 2007, "Benford's Law Applied to Hydrology Data-Results and Relevance to Other Geophysical Data", Mathematical Geology, vol: 39, pp. 469-490

Nye, J. And Moul, C. 2007, "The Political Economy of Numbers: On the Application of Benford's Law to International Macroeconomic Statistics", The B.E. Journal of Macroeconomics, vol 7, no. 1, Article 17.

Rauch, B., Göttsche, M., Brahler, G., and Engel, S. 2011, "Fact and Fiction in EU-Governmental Economic Data", German Economic Review, vol. 12, no. 3, pp. 243-255.

Slemrod, J. 1985, “An Empirical Test for Tax Evasion”, The Review of Economics and Statistics, vol. 67, no. 2, pp. $232-238$.

Thomas, J. K. 1989, “Unusual Patterns in Reported Earnings”, The Accounting Review, vol. 64, no. 4, pp. $773-787$. 
Uzuner, M. T. 2014, "Benford Yasasının Borsa İstanbul'da İşlem Gören Bankaların Konsolide Bilançolarına Uygulanması", Finansal Araştırmalar ve Çalışmalar Dergisi, vol. 5, no.10, pp. 73-82

Zahra, S. A., Priem, R. L. and Rasheed, A. A. 2005, "The Antecedents and Consequences of Top Management Fraud". Journal of Management. vol. 31, no. 6, pp. 803-828. 